\title{
Human Right To Safe Water Of Hard To Reach Areas In Bangladesh: Challenging Issue For GOs And NGOs
}

\author{
Anjelika Hasan \\ Department of Law \\ European University of Bangladesh
}

\begin{abstract}
Right to safe water for every citizen has not been ensured yet because water has not been mentioned as a Human Right in the Bangladesh Water Act 2013. National water coverage is about 86 percent. Only 10 percent population has access to piped-line water supply service. The national budget for safe water supply is urban biased for the fiscal year of 2014-15. The especial budget has not been allocated for safe water for hard-to-reach areas viz. char, costal, drought, flood, haor and hilly. Though local government is accountable to ensure safe water but LGIs are not aware regarding their roles, responsibilities and mandate to provide safe water to the people. The main objective of this paper is to examine to what extent the VDCs in close cooperation with LGIs, NGOs and INGOs are able to provide safe water to establish Human Right to the hard-to-reach people in Bangladesh.
\end{abstract}

Keywords: Human Right, Safe Water, Hard to Reach, Challenging Issue

$$
\begin{aligned}
& \text { تلخيص }
\end{aligned}
$$

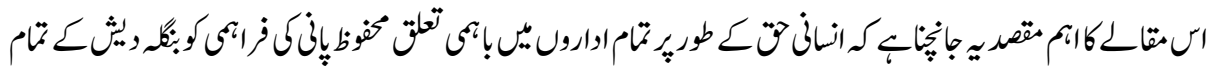

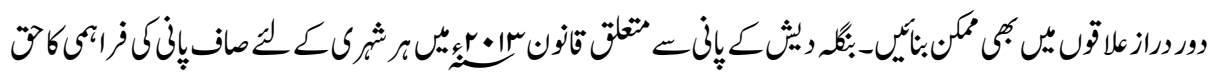

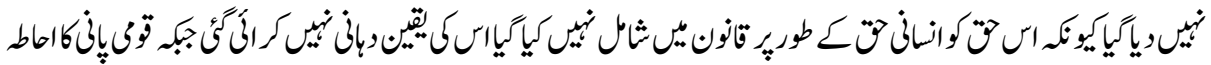

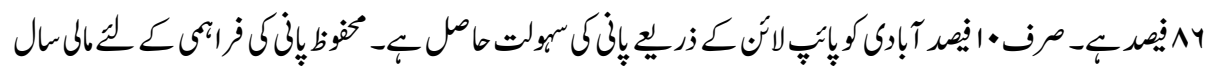

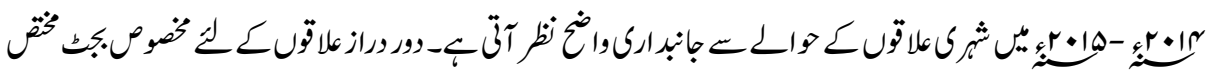

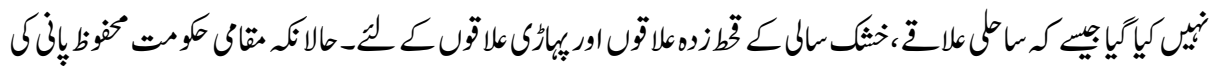

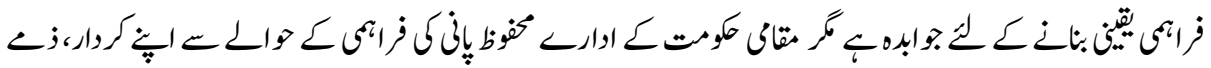

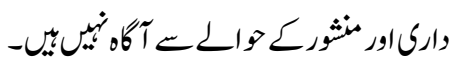

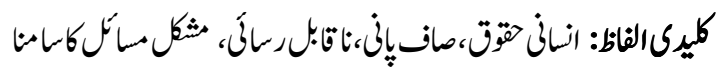




\section{Introduction}

The United Nations General Assembly explicitly recognized and acknowledged that clean drinking water is essential to the realization of all human rights. The Resolution calls upon States and international organizations to provide financial resources help capacity-building and technology transfer to help countries, in particular developing countries, to provide safe, clean, accessible and affordable drinking water for all. The pre-requisite of healthy life is availability of safe water for drinking and cooking purposes. That is why, development planners as part of economic growth have been focusing increasingly on essential public services such as water supply (Kalbermatten et al., 1980). But the reality is that a large proportion of the world population who lives in developing countries are still deprived of having access to get safe water. Among them, the poor are the mostly affected as they lack both the means to get such facilities and knowledge on how to minimize the negative effects of unsafe water (Larcimont, 1995). Like most of the developing countries, Bangladesh is not an exception in this regard. Bangladesh with a very poor infrastructure and resources, has committed to provide safe drinking water to its people, which was endorsed by Non-Government Organizations (NGOs), donors and media. NGOs in Bangladesh have played a significant role in implementing development programs although such programs were initiated by the government itself in the early 1960s. By this time Bangladesh has achieved remarkable progress in water sector. But all the corners of the country are not enjoying the safe water facilities equally (Ali, 2012).

Unfortunately, most of the government programs failed especially in rural areas because a community-wide spirit did not develop and hopes for village-wide co-operation were not realized (Lovell, 1992). Consequently, safe water in Bangladesh is unimpressive. Although national coverage of water supply is 97.8 percent but the scenario at the hard to reach areas in Bangladesh is quite different and alarming. Under the circumstances, NGO Forum for Public Health came forward in facilitating the implementation the project entitled "Enhancing governance and Capacity of Service Providers and Civil Society in Water Supply with the financial support of European Union. The project is under implementation covering 59 hard to reach unions of 6 geo-hydrological zones in Bangladesh. The project has already been started on January, 2013 and it will continue up to December, 2016. The government's comprehensive plan and public-private partnership are the main pre-requisites to ensure people's rights to water, The main focus of this paper is to examine to what extent water service providers steer the governance in promoting sustainable safe water supply in vulnerable geo-physical settings in Bangladesh. 


\section{Conceptual Issue}

Safe water means water that does not harm to person if he or she comes in contact with it. The most common use of this term applies to drinking water, but it could also apply to water for swimming or other uses. To be safe, the water must have sufficiently low concentrations of harmful contaminants. The list of harmful contaminants includes bacteria, viruses, pesticides, petroleum products, some metals and metalloids, strong acids, and many more substances. It is important to keep in mind that water can be safe for one person and may be unsafe for another. If any individual immune system is weak, he or she is a young child or an elderly person, or pregnant or a nursing mother, she is more susceptible to contaminants in drinking water than the rest of the population.

The human right to water is indispensable for leading a life in human dignity. It is a prerequisite for the realization of other human rights. It is defined the right to water as the right of everyone to sufficient, safe, acceptable and physically accessible and affordable water for personal and domestic uses. On the other hand, around 25 percent of the country considered hard-to-reach areas which cover 1,144 unions of 257 upazilas of 50 districts. More specifically hard-to-reach areas are defined as the people living in chars, haors, coastal areas, hills, flood, and drought zones where people do not get safe water all the time.

\section{Research Methodology}

The paper is based on data is taken from the project entitled Effects of Community Integration on Capacity Building of Local Actors in Water Supply and Sanitation in Vulnerable Geo-Physical Zones in Bangladesh. The author was research associate of the project. Several methods and techniques were applied to conduct this research project.

\section{Area of Research}

To conduct this research, six areas have been selected from 59 unions of 27 upzilas of 25 districts with particular focus on hard to reach agro-ecological zones of overall Bangladesh. The specific 6 areas are Nikrail union of Bhuapurupazila of Tangail district, Tentulia union of Mohangonjupozila of Netrokona district, Talanda union of Tanoreupozila of Rajshahi district, ChhotoBhaklauinion of Goalandaupozila of Rajbari district, Fingri union of SadarSatkhira of Satkhira district, Ghilachari union of Nariar Upozila of Rangamati district. The main objective of this selection is to get representative information on overall improvement in public health conditions especially safe water and sanitation of the diversified targeted communities. It should be mentioned that the main reason was behind the selection of these specific hard to reach areas was to cover the 

and NGOs

coastal area, hilly area, drought prone area, haor area, char area and flood prone area in to get representative data.

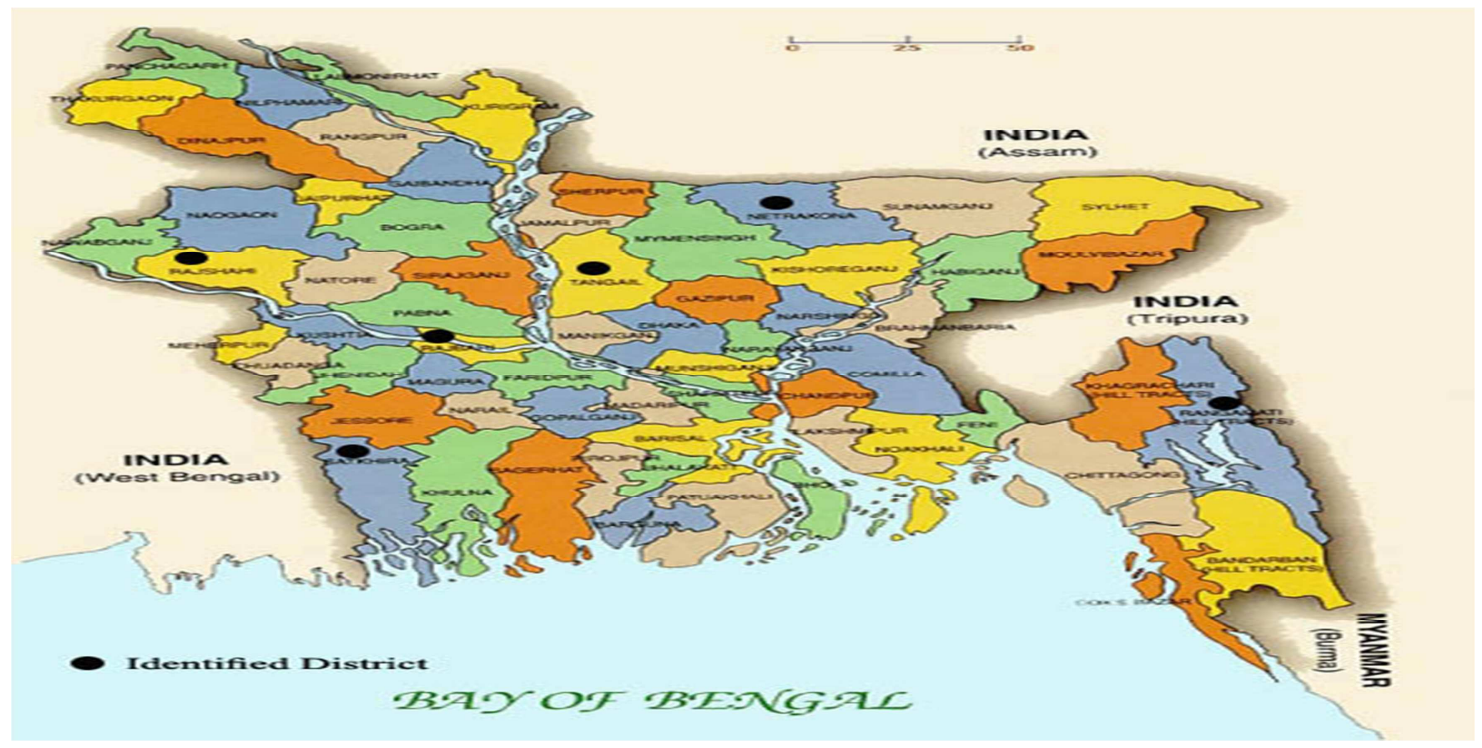

\section{Methods of Data Collection}

Observation, FGD, use of key informants and case study methods were applied in order to collect reliable and authentic information on this personal as well as community issues. Observation method is applied in every stages of data collection to find out the reliability validity of the data. The main emphasis was given on FGD and case study method. The four groups of people were selected to conduct FGD from the selected six areas. They were chairman and members of union, chairman, vice chairman, secretary and members of VDC, personnel of partner NGOs of each individual VDC and beneficiaries of six VDCs. About 8 to 12 respondents brought together to collect information on specific issue from different voices. A guide check list was prepared keeping in view with the objectives of this study and it was administered individually to conduct the survey using the methods and techniques of FGD. Case study was used to collect in-depth information on specific issue. The key informants were selected from the cross-section of people to supplement the data collected using the other methods. Secondary data also collected to strengthen the primary data. Both qualitative and quantitative techniques were applied for analysis of the data, but emphasis is given on qualitative technique. 


\section{Situation of Safe Water}

The purpose of using water of hard to reach areas has been classified into two categories viz. water for drinking and cooking. It has been found that 96 percent people used safe water and the rest of 4 percent use unsafe water for drinking (NGO Forum for Public Health, 2013). Among the total safe source, about 65.6 and 22.7 percent people collect drinking water from shallow tube-wells and deep tube- wells respectively. It is found in the figure-1 that access to safe water for drinking is very poor in hilly areas compared to hard-to-reach areas. It has been found that some of the people have to collect safe water distance places. About 76.6 percent people collect safe water up to 50 meters distance, 8.4 percent51to 100 meters and 3.1 and 12 percent collect safe water from 101 to 150 meters and more than 150 meters distance respectively. It should be noted that in hilly area people also collect safe water from rain water harvesting but it does not cover the whole year because of meager amount.

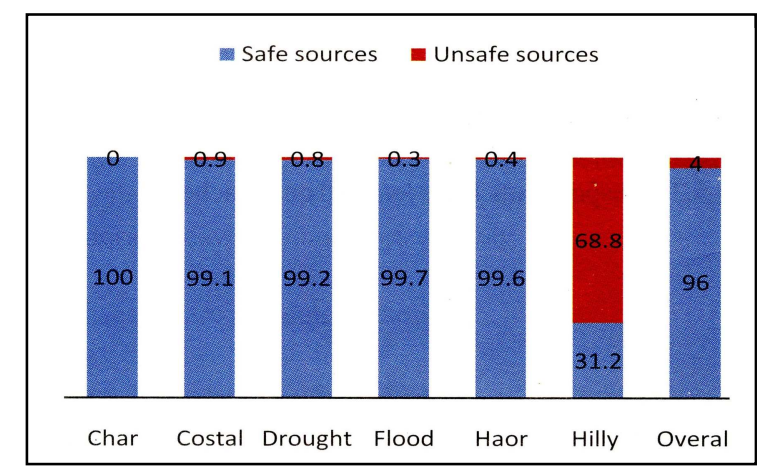

Figure-1: Source: NGO Forum for Public Health, 2013

On the other hand, about 71.8 percent people collect safe water from different sources for cooking purpose. It is found that only 56.4 percent collect water from shallow tube well. It is interesting to note that about 68.2 and 68.8 percent people of coastal and hilly areas have use unsafe water for cooking purpose. Similarly, about 35.2 and 28.2 percent people flood and haor areas Use unsafe water cooking respectively. The findings Indicate overall 28.2 percent people of hard to reach areas use unsafe water for cooking purpose. On the Other hand, 71.8 percent over all people use safe water for Cooking purpose. The zone wise result of using safe and unsafe water for cooking indicates a significant variation. 


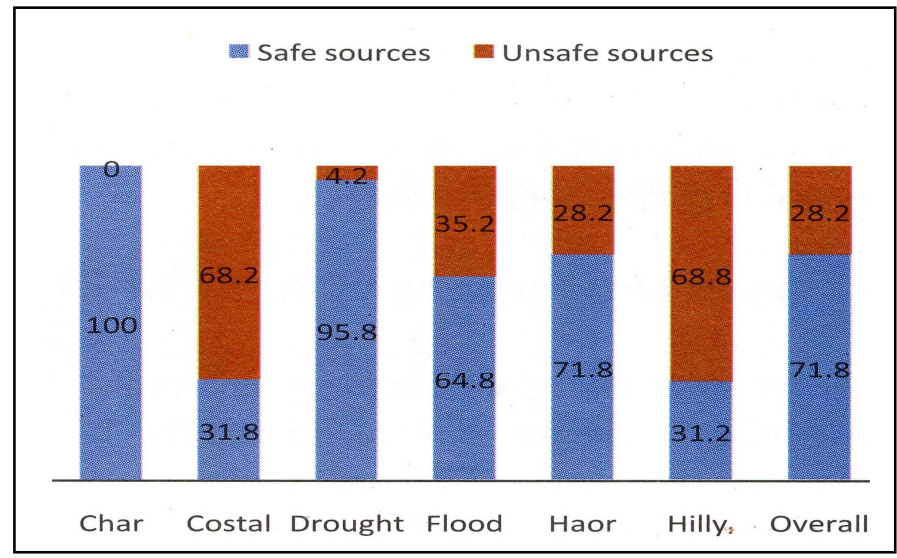

Figure-2: Source: NGO Forum for Public Health, 2013

\section{Human Right to Safe Water}

Bangladesh has voted for UN resolution 2010 which provided access to safe water and sanitation as human rights. However, access to safe potable water has not been termed as human rights in the Bangladesh water act 2013. Even the penultimate version of the act had considered access to safe water as human right. It is found that the Government's stood in the UN general assembly and in its own parliament are not similar. Now the challenge is execution of the act. WARPO is the focal body to execute the act. It is basically is a centralized organization. It has very limited capacity and as a result without delegating responsibility to the Local Government Institutions (LGIs), it is be extremely difficult for WARPO to execute the act at the ground level especially in rural areas. Under these circumstances, the committee needs to delegate responsibilities to the local government.

The existing tariff system is highly biased towards the rich who are served by the public utilities. It also found that the existing flat rate of water is the main reason of prevailing water misuse; and perhaps one of the leading causes of water shortage that we experience in Dhaka city. In the present rate, people buy one thousand liter of potable water for just little over seven and a half taka or one liter of water for just 0.007 taka. This is not even the production cost of water. The government is providing subsidy. This ultimately means that subsidizing water to encourage people to use or misuse more water. For example, people flush toilet as many times as may need, or wash car, water your garden with potable water while there are many people, which is about one third of the total population of the city, living in the slums pay roughly 200 times more than this rate to collect water from the informal sources to meet their thrust. This should not be continued forever. Consequently, a progressive tariff system needs to be introduced, based on the principal of "more use more pay. Dhaka WASA can generate additional annual revenue if 
a very soft kind of progressive tariff system is introduced. This on the one hand will prevent misuse of water; thus, WASA do not have to spend more money to increase supply. On the other hand, the increased revenue could be used to bring the poor slums dwellers as well as hard-to-reach people into the service coverage. There need to be developed efficiency in the water management as well as promote justice in the water governance.

The issue of discrimination and urban-rural disparity in making fresh water available to the people often comes up in discussion. It has been observed that the public sector allocation and expenditure for water and sanitation for over the past several years and it is very surprising to see huge discrimination between rural and urban as well as within the urban. In the Five Year plan of 2008-9, the allocation to rural areas was 30 percent of the total allocation for water supply and sanitation. Since then, it has been gradually decreasing. Allocation to rural areas came down to as low as 5.9 percent of the total allocation for water and sanitation in Five Year plan of 2011-12. On the other hand, although the urban areas receive the bulk of the public sector allocation, but most money unfortunately goes to the big cities. In the Five Year plan of 2011-12, six big cities received almost two-third of the total allocation that went to the urban while the rest of the cities and municipalities altogether got 25.9 percent. Further disaggregation of the allocation in the same Five Year suggests that among the six big cities, Dhaka and Chittagong has taken away almost all the money, 54.2 and 37.1 percent respectively. If we look at the project lists of these two cities, we will be surprised to see that all the big budget projects are to service the rich people, either to replace the old sewerage network or bringing new settlements into the coverage. There is hardly anything to service the poor who are more than one third of the total population of the city and key to the economy of the cities. Similarly, people of hard-to- reach areas are deprived to get safe water in Bangladesh and they are beyond the scenario of right to safe water for drinking and cooking purposes.

\section{Joint Effort to GOs and NGOs}

The people living in chars, haors, exposed coastal areas, hills, flood and extreme draught areas are suffering due to lack of safe water. For example, an indigenous woman living in the Chittagong Hill Tract has to walk long way and long time in dangerous hilly path to collect small amount of water. On the other hand, scarcity of safe water is one of the impediments maternal and child health in the coastal areas. Malnutrition among children is significantly higher in hard -to reach areas compared to plan land. People cannot maintain personal hygiene in disaster period due to water crisis. Under the circumstances, both GOs and NGOs come forward to provide safe water to the people of hard-to-reach areas involving the civil society, VDCs and LGIs through establishing good governance. 


\section{Village Development Committee (VDC)}

The Village Development Committee (VDC) is a village based organization which is established for the promotion of self help. The concept of self-help promotion means to develop the capacity of the people to help themselves by proper utilization of their local resources to stand on their own feet with the technical support from external sources for a specific period of time (Sarker, 2001: 6). The VDC is constituted by 15-17 members with the minimum 30 percent female members, 30 percent poor and hard core poor and at least one elected member of UP. The structure of VDC is one chairman, one vice-chairman, one secretary, one cashier along with 11-13 members. The promotion of VDC started by training carefully selected local partner NGOs. The WatSan Partnership Project (WPP) teams of these partner NGOs consisted of 5 members: one community organizer, two male and two female field facilitators. They were taught how to approach and build rapport with the village community, identify resource persons, how to initiate participatory thought processes and how to facilitate the formation of a VDC. The principles behind the formation of VDC were empowering of people's organization for development of private sector for safe water, sanitation and improvement of public health with the close cooperation of local governance system through inter mediation of NGO. A diagram is given below to get the clear idea about the four components associated with the formation of VDC.

\section{Components of VDC}

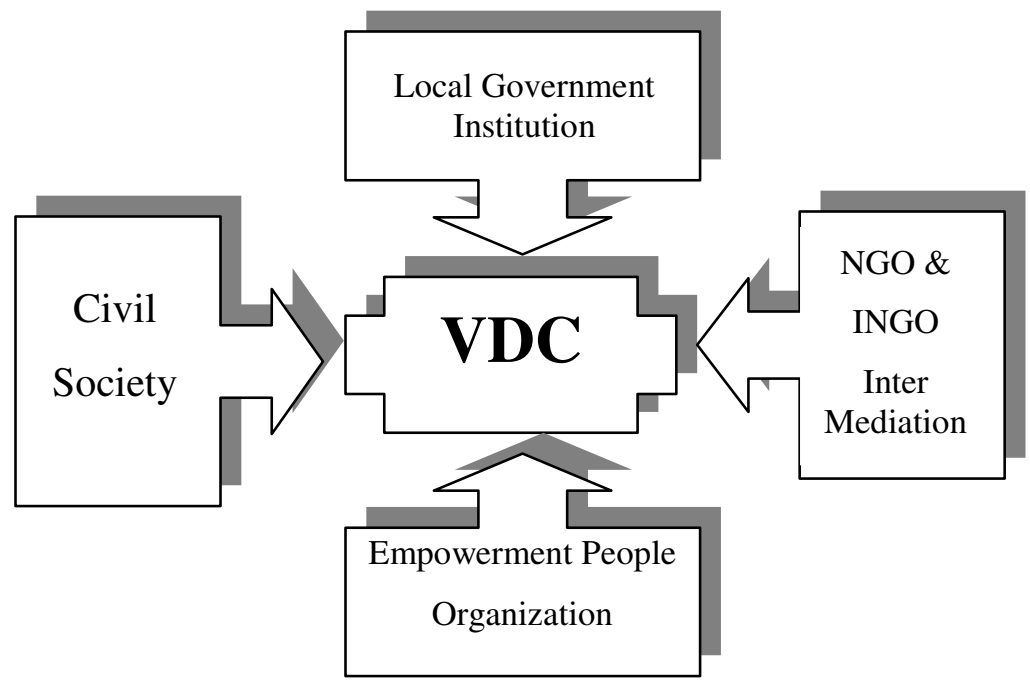

Figure-3: Four Components Associated with the Formation of VDC

The VDC was form with the initiative of the concern Partner NGOs. Once a VDC was formed, it is conducted a number of Rapid Rural Appraisal (PRA) exercises to analyze 
the water and sanitation situation in the village to assess needs in order to prepare plan of action and implement the plan through the process of community management involving the local government institution with the initiative of stakeholders. In providing safe water services, VDCs are the grass root level organization. It is the plat form of the civil society to raise their voice to the local government intuitions to establish their right to safe water.

\section{Partnership Network}

Partnership network is a flow of relationship, which is established among the international NGOs through their involvement in prescribed responsibilities in order to develop the capacity of the partner NGOs. The partner NGOs provide training to their respective VDCs. The main thrust of training is to empower the VDCs keeping in view to solve their problems by their own effort using the different tools viz. need assessment, planning and implementation of plan, mobilization of local resources, development of sense of ownership, holistic village development ideology, financial management, monitoring and evaluation. A partnership net work model is given below to get the clear picture how the network efforts empower the VDCs to improve the WatSan and public health situation at the grass root level.

\section{Partnership Network}

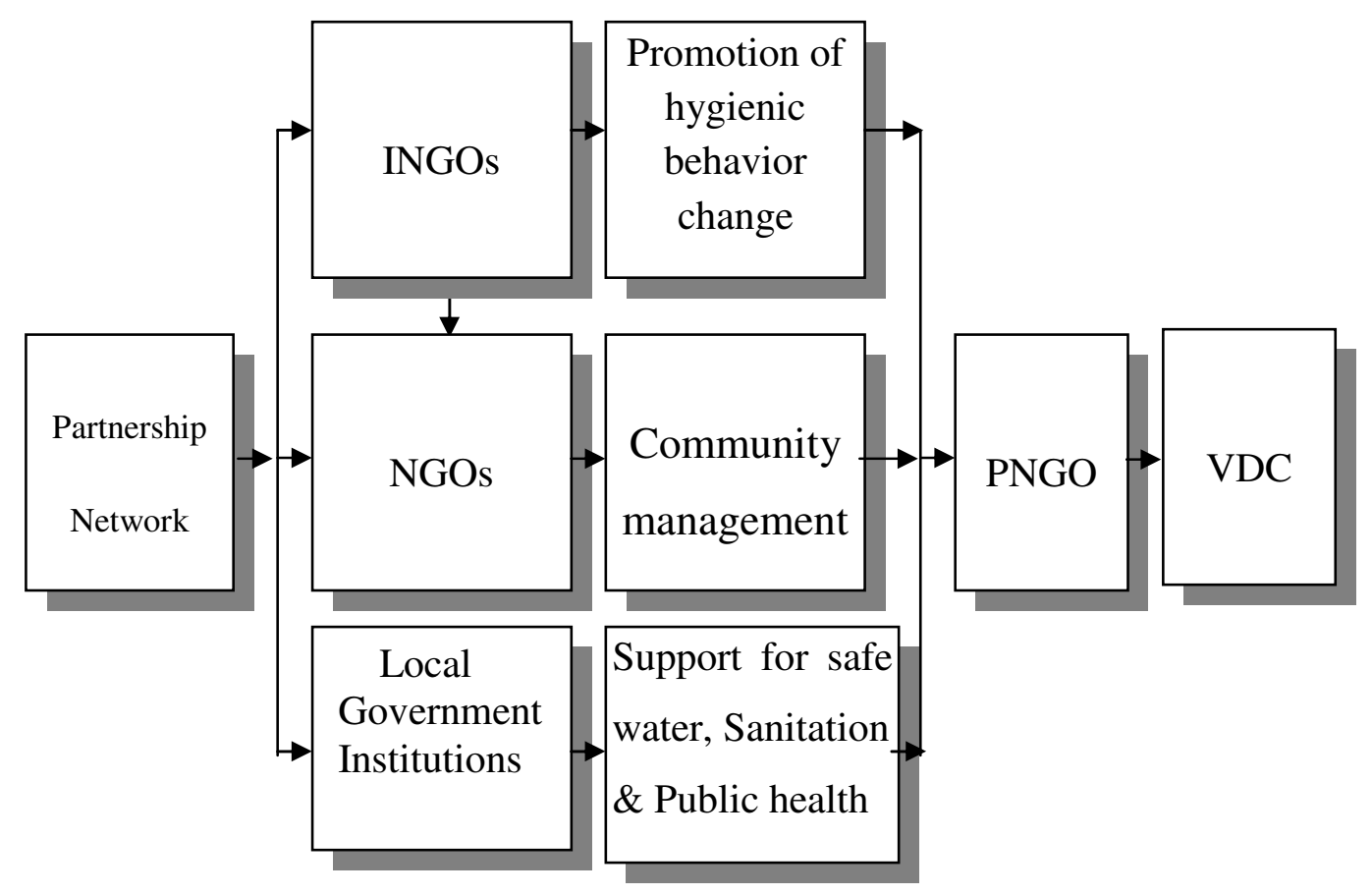

Figure-4: Partnership Network Model 
Partnership network model represents that the International NGOs is a donor organization is providing financial support to national $\mathrm{NGO}, \mathrm{NGO}$ in order to help to solve the problem of safe water and sanitation at the grass root level in order to improve the public health and reduction of morbidity and mortality as well as quality of life of the pro-poor. NGO steps forward involving the Local Government Institutions (LGIs), Partner NGOs, VDCs and civil society. Partner NGO promotes community management for rural water and sanitation services through VDC. Moreover, partner NGO creates greater awareness of sanitation and personal hygiene among the targeted people in close cooperation of VDCs with the help of Union Parishad involving the civil society. This joint effort contributes to strengthen good governance. The main goal of the partnership network is to ensure community management and participation in hygiene behavior changes and the improvement of user access to, and sustainable use of water and sanitation facilities (DASCOH, 1997: 5). It should be mentioned that the partner NGOs were given training to act as facilitators to promote self-help capacity of the VDCs to solve the problem of safe water.

\section{Challenges to Right to Water}

The VDC is institutionalized at the grass root level keeping in view bringing a positive change or progress on WatSan to improve the quality of life and well being for the poorer section of people. The VDCs are found immature because they are still in infant stage of one and half year of age. It is a learning process of a pilot project (Eppler and Shayamual, 1998). The main mission of INGOs is to strengthen the capacity of VDCs to promote self-help in connection with the improvement of WatSan through PNGOs. It has been found that about sixty percent members of VDCs are capable in WatSan identification, planning, mobilization of utilization of local resources, implementation of plan, financial management, evaluation and monitoring, etc. in order to solve the WatSan problems. But the sustainability of their capacity development of VDCs is in question if the INGOs and PNGOs withdraw their support. Under the circumstances following challenges are to be faced in order to sustain the VDCs in order to get safe water as well as to change the hygiene behavior which will contribute to improvement of public health in hard-to reach areas of Bangladesh.

1. Counseling and motivation should be more intensive by the PNGOs in order to involve the VDC members in training, group discussion and other capacity development programs for strengthening of WatSan in order to get better health.

2. The linkage between the VDCs and the local self-government should be developed for the sustainability of the VDCs. It is not feasible for a group of people to bring about necessary hygiene behavior change for the improvement of their lives unless they are involved with the main stream of collective action. 
3. VDCs will eventually contribute to a better life for the family members of weaker section of the village people. But the key persons of VDCs should have the vision of the ideal village and efforts should be given to achieve this goal.

4. The authoritarian attitude of the facilitators of PNGOs should be avoided in order to build up the sustainable self-help capacity of VDC members.

5. Rain water harvesting system should be introduced to meet up the needs of water especially for drinking and cooking purposes as an alternative option. The advocacy should be initiated at the different levels involving the media to use rain water.

6. The INGOs should continue their programs to take new villages for the formation of VDC and withdraw support from the matured VDCs through implementing the phase out policy. In this way all the villages of Bangladesh should be brought under this scheme of VDC keeping in view to improve the better quality of life and well-being for the disadvantaged people at the village level.

7. The Ghilachhari union of Naniar Char Upozila of Rangamati district may be selected as a model union to established mission of good governance in providing safe water services through stakeholders.

\section{References}

Ali. Ayub M.(2012). Coping with Coastal Challenges, Dhaka, NGO Forum for Public Health.

DASCOH (1997). Annual Report of Development Association for Self-reliance Communication and Health.

Eppler, Peter and Shayamal K. Saha (1998). Development of Self-help Organizations at Village Level, DASCOH, Dhaka.

Kalbermatten J. M., D. S. Julius and C. G. Gunnerson (1980). Appropriate Technology for water Supply and Sanitation: Technical and Economic Options, Research Project RPO 671-46, Washington DC: World Bank.

Larcimont C. H. (1995). Water Supply and Sanitation in Bangladesh, Watsan, Special Issue, June 1994- March 1995.

Lovell C. H. (1992). Breaking the Cycle of Poverty: the BRAC Strategy, University Press limited, Dhaka. 
22 Human Right to Safe Water of Hard to Reach Areas in Bangladesh: Challenging Issue for GOs and NGOs

NGO Forum for Public Health (2013). Baseline Survey Report on Enhancing Governance and Capacity of Service Providers and Civil Society in Water Supply and Sanitation Sector.

Sarker, Profulla C. (2001) Self-help Capacity at Village Level: Mid Term Assessment of Its Growth and Level of Sustainability: DASCOH, Dhaka.

Anjelika Hasan is Assistant Professor in the Department of Law, European University of Bangladesh, Dhaka. 